a significantly lower manganese content in the leaves of infected plants. These cuttings showed no obvious growth differences.

While it would be premature to attempt an interpretation of these results, it may be concluded that inoculation with the sporocarps of an Endogone sp. produced endotrophic mycorrhizal infection, and, either directly or through its influence on the soil, affected the growth of plants, the balance of nutrient uptake from the soil, and the mineral content of both root and shoot.

I thank the Plant Analysis Section of this Station for the spectrographic analysis.

East Malling Research Station, Maidstone, Kent.

Jan. 25.

1 Garner, R. J., Hatcher, E. S. J., Nicoll, C. P., Rep. East Malling Res. Sta. for $1953,158(1954)$.

${ }^{2}$ Mosse, B., Nature, 171, 974 (1953).

s Mosse, B., Ann. Bot., 20, 349 (1956).

\section{Spectral Sensitivity of an Echinoid}

IN a paper published in 1954, I showed that the echinoid Diadema antillarum Philippi reacts to shading by spine movements ${ }^{1}$.

The sensitivity of isolated pieces of test-bearing integument, spines and radial structures was determined in the region of the spectrum between 400 and $600 \mathrm{~m} \mu$ by means of interference filters transmitting wave-bands 8-11 m $\mu$ wide and a lamp of known colour temperature, placed at a finite distance from the test. The centre of the emitted beam was radial with respect to the curvature of the test and its intensity was controlled by neutral filters. The light beam, projected for $3 \mathrm{~min}$. on to the inside or outside of the preparation, was interrupted by releasing a spring-loaded shutter and the resulting spine movement was recorded photographically. The minimal light-energy required to elicit

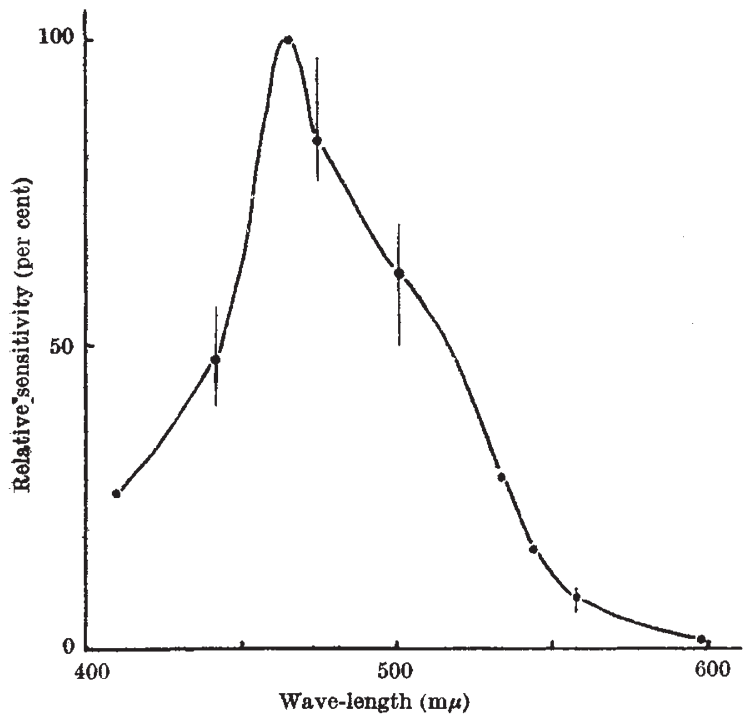

Fig. 1. Spestral sensitivity of Diadema antillarum, determined by stimulating the inside of the test. The vertical lines intersecting the curve show the maximum ra
at each point spine movement on cutting off the beam was determined for each wave-band; the reciprocal of this value is an index of sensitivity. Energy distribution over the spectrum was obtained from Wien's radiotion formula, appropriate corrections being made for the characteristics of the optical system employed.

One hour after removal, the sensitivity of each preparation to light of a given wave-band was found to be constant.

Sensitivity was consistently maximal in the blue region of the spectrum, falling off steeply on either side, so that the animal appeared relatively insensitive to wave-lengths shorter than 440 and longer than $530 \mathrm{~m} \mu$.

When the test was stimulated internally, sensitivity was maximal at $465 \mathrm{~m} \mu$. The action spectrum is shown in Fig. 1. When stimulated externally, the results were inconsistent, but most pieces showed a maximum at either 465 or at $475 \mathrm{~m} \mu$. The results of external stimulation must be regarded with caution, since unavoidable changes in the stance of the spines must necessarily affect the amount of light reaching the outside surface.

A full account of this work will be published later.

N. Mrriote

M. Yoshid A

Department of Zoology,

Bedford College,

Regent's Park,

London, N.W.1. Jan. 28.

${ }^{1}$ Millott, N., Phil. Trans., B, 238, 187 (1954).

\section{Simuliidae attracted at Night to a Trap using Ultra-Violet Light}

Since the end of May 1955, a light-trap for insects has been in use every night at Kincraig, in the Spey Valley of Inverness-shire, as part of an investigation of the relationship of weather conditions and insect activity. This work is being carried out on behalf of the Agricultural Research Council.

A remarkable feature of the eatches has been the large numbers of bloodsucking Diptera of the family Simuliidae, a group of great medical and veterinary importance in many parts of the world. This indicates that Simuliidae exhibit considerable night activity, a fact not hitherto recognized.

The captures during the two years have been as follows :

1955: May (last 10 nights only), 3; June (20 nights), 50 ; July, 105 ; August, 274; September, 191 ; October, 214 ; November, 176 ; December, 20, the last captures being 12 on the night of December 6 . Total for year, 1,033 .

1956 : April, 1 on April 30 ; May, 30 ; June, 51 ; July, 155 ; August, 482 ; September, 1,419 ; October, 1,360 ; November, 557 ; December, 156 (including 95 on December 4). Total for year, 4,211.

1957 : January, 3 ; February, 1 ; March, 13.

The type of trap used is the Rothamsted trap ${ }^{1}$, which is particularly good for Diptera ${ }^{2}$. The source of light was a 200-W. 'Sieray' Dual lamp which has a mercury vapour circuit, but fits into an ordinary $240-\mathrm{V}$. supply without accessory apparatus. The lamp is at a height of about four feet from the ground, overlooking open birch-heather association, and is about a quarter of a mile from the nearest running 